\title{
ANALISIS FAKTOR-FAKTOR YANG MEMPENGARUHI LENGTH OF STAY (LOS) PASIEN ANAK DI INSTALASI GAWAT DARURAT (IGD)
}

\author{
Hellena Delia*) ; Oswati Hasanah ${ }^{\mathrm{b}}$; Riri Novayelindac; Enni Purwantid \\ a, b,c, d KJFD Maternitas Anak Fakultas Keperawatan Universitas Riau \\ Jl. Pattimura ; Pekanbaru ; Riau
}

\begin{abstract}
LOS pasien anak di UGD merupakan faktor yang dapat mempengaruhi mortalitas di UGD. Terdapat beberapa faktor yang dapat mempengaruhi LOS pasien anak di UGD. Penelitian ini bertujuan untuk mengetahui faktor-faktor yang mempengaruhi LOS pasien anak di UGD. Penelitian ini merupakan penelitian observasional analitik dengan pendekatan cohort retrospektif. Sumber data yang digunakan pada penelitian ini adalah data sekunder. Data diperoleh dari rekam medis pasien selama periode Januari hingga September 2018. Tekhnik pengambilan sampel adalah non probablity sampling dengan jumlah sampel 196 orang. Analisis yang digunakan adalah chi square dan regresi logistik. Hasil analisis bivariat menunjukkan terdapat hubungan antara cara kedatangan, konsultasi dokter spesialis, pemeriksaan diagnostik dan laboratorium, disposisi final dengan nilai $p$-value< 0,05. Hasil analisis multivariat menemukan bahwa variabel yang paling berpengaruh adalah bagaimana-untuk tiba, di mana pasien rujukan memiliki 2,544 kali lebih banyak kemungkinan LOS dibandingkan dengan datang sendiri. Diharapkan hasil penelitian ini dapat digunakan sebagai dasar untuk pertimbangan dalam mengembangkan protokol dan kebijakan rumah sakit untuk meningkatkan kualitas layanan.
\end{abstract}

Kata kunci: Length of stay (LOS), Anak, IGD

\begin{abstract}
Abstrak
[ANALYSIS OF FACTORS INFLUENCE LENGTH OF STAY (LOS) IN PEDIATRIC PATIENT IN THE EMERGENCY DEPARTMENT (ED)] Several factors can affect the LOS of pediatric patients in the ED. This study aims to determine the factors that influence the LOS of pediatric patients in the ED. This study was an observational analytic study with a retrospective cohort approach. The data source used in this study was secondary data from the patient medical records during the period from January to September 2018 in the ED. The samples amounted to 196 people. The tests used in this study are chi-square and logistic regression. The bivariate analysis shows there was a relationship between how the arrival, consulting medical specialist, diagnostic and laboratory examination, and the final disposition LOS pediatric patients in the ED (p-value <0.05). The multivariate analysis found that the most influential variable was the how-to arrive, where the referral patient had 2,544 times more possibility of LOS compared to coming alone. It was hoped that the results of this study can be used as a basis for consideration in developing hospital protocols and policies to improve service quality.
\end{abstract}

Keywords: Length of stay (LOS); Children; ED

\section{Pendahuluan}

Kondisi kegawatdaruratan dapat mengancam siapa saja, termasuk anak-anak dan membutuhkan penanganan segera. Perawatan darurat pada anak-anak berbeda dari orang

*) Correspondence Author (Hellena Deli)

E-mail: hellenadeli.hd@gmail.com dewasa. Instalasi gawat darurat (IGD) merupakan garda terdepan dirumah sakit yang memberikan perawatan kesehatan kepada pasien yang mengalami kondisi gawat darurat. IGD merupakan suatu unit pelayanan khusus yang memberikan perawatan segera atau mendesak tanpa janji sebelumnya. Pasien yang 
datang ke IGD dapat secara pribadi ataupun melalui ambulan dengan berbagai keluhan, dimana keluhan tersebut dapat mengancam jiwa (life threatening) dan membutuhkan penanganan segera (Chonde, Ashour, Nembhard, \& Kremer, 2013).

IGD bertanggung jawab mulai dari penerimaan, triase, penilaian awal, stabilisasi, manajemen terhadap anak-anak yang mengalami kondisi akut, cedera dan rujukan ke perawatan berkelanjutan (Australasian College for Emergency Medicine, 2012). Kematian anak-anak dirumah sakit sering terjadi dalam 24 jam pertama penerimaan. Kematian ini dapat dicegah jika anak-anak yang sakit diidentifikasi segera setelah mereka tiba di fasilitas kesehatan dan pengobatan segera dimulai. Pencegahan ini dapat dihindari dengan cara triase dan waktu tunggu (length of stay) di IGD cepat (WHO, 2016).

Prinsip pelayanan di IGD adalah cepat dan tepat waktu, namun peningkatan jumlah pasien yang mengunjungi IGD dan ketersediaan sumber daya yang tidak memadai dapat mengakibatkan waktu tunggu pasien terutama pasien anak menjadi meningkat (Ronca, 2014; Li, et al, 2013). Lamanya waktu tunggu dan waktu perputaran pasien telah menurunkan kualitas hasil perawatan dan kepuasan pasien (Sayah, Rogers, Devarajan, Kingsley-Rocker, \& Lobon, 2014).

Kunjungan anak-anak ke IGD pada 6 negara bagian di Amerika pada tahun 2010-2011 sekitar 2,9 juta anak. Mayoritas anak yang mengunjungi IGD berusia 8 tahun. Negara yang memiliki kunjungan terbanyak adalah California, Florida dan New York (Goto et al, 2017). Kunjungan pasien anak ke IGD di Asia bervasiasi. Berdasarkan hasil penelitian yang dilakukan oleh Li et al (2013), jumlah angka kunjungan anak ke IGD di rumah sakit Taiwan pada tahun dalam kurun waktu 1 tahun (2006-2007) adalah 29.035 pasien anak. Sedangkan di Thailand angka kunjungan pasien anak ke IGD dalam 10 tahun terakhir berjumlah 122.037 orang dengan rata-rata 12.000 kunjungan pertahun. Mayoritas anak mengunjungi IGD pada sift sore (Pandee et al, 2015).

Belum ada data pasti yang menggambarkan jumlah angka kunjungan pasien anak ke seluruh IGD di Indonesia. Namun berdasarkan hasil penelitian yang dilakukan oleh Dharmawati et al (2012) jumlah angka kunjungan pasien anak di IGD rumah sakit Dr. Soetomo dalam rentang waktu 1 tahun angka kunjungan pasien anak di IGD berjumlah 5.835 orang dengan rata-rata 486 pasien per bulan.

Emergency Departement Length of Stay (ED LOS) atau yang lebih dikenal dengan waktu tunggu merupakan waktu yang diukur saat pasien diputuskan oleh dokter atau tenaga kesehatan lainnya untuk masuk ke IGD hingga pasien pulang atau pindah ke ruangan $(\mathrm{Li}$, et al, 2013; Ronca, 2014). Berdasarkan hasil penelitian yang dilakukan oleh Li et al (2013) rata-rata LOS di rumah sakit Taiwan adalah 2,6-4,7 jam, sedangkan di Indonesia penelitian terkait LOS pasien anak belum pernah dilakukan. Waktu tunggu untuk pasien di IGD yang disaran tidak lebih dari 4 jam (Excellence. B.P, 2013 ; Horwitz et. al, 2010).

ED LOS yang lama dapat mengakibatkan terjadinya peningkatan angka mortalitas dan morbiditas. Beberapa hasil penelitian menunjukkan bahwa terdapat hubungan antara ED LOS dengan peningkatan angka mortalitas, dimana terjadi peningkatan angka mortalitas sekitar 2,5\% pada pasien yang keluar dari IGD kurang dari 2 jam menjadi $4,5 \%$ pada pasien yang keluar dari IGD dalam waktu 12 jam atau lebih (Ronca, 2014).

Banyak faktor yang berhubungan dengan ED LOS pasien anak di IGD salah satunya adalah jumlah pemeriksaan laboratorium, usia, konsul dokter spesialis, jenis IGD serta jenis triase yang digunakan. Berdasarkan penelitian yang dilakukan oleh Mace et al (2013) terdapat hubungan antara usia, jumlah pemeriksaan laboratorium, konsul dokter spesialis dengan ED LOS pada pasien anak di IGD.

\section{Metode}

Penelitian ini merupakan penelitian observasional analitik dengan pendekatan cohort retrospeksi. Penelitian ini menggunakan sumber data sekunder berupa rekam medis dan laporan register pasien selama periode Juli hingga September 2018 di bagian IGD dan rekam medis rumah sakit. Metode pengambilan sampel adalah non probablity sampling dengan jumlah sampel yang memnuhi kriteria berjumlah 196 orang. Semua data yang diperoleh akan dianalisis dengan analisis univariat, bivariat dan multivariate. Uji chi square digunakan untuk melihat hubungan setiap variable dan regresi logistik digunakan nuntuk melihat variabel yang paling berpengaruh terhadap LOS pasien anak di IGD. 


\section{Hasil dan Pembahasan}

\section{a. Karakteristik Pasien}

Berdasarkan hasil penelitian, tersaji gambaran karakteristik responden yang mengunjungi IGD dapat dilihat pada Tabel 1. Didapatkan bahwa anak laki-laki mengunjungi IGD lebih banyak dibandingkan anak perempuan sebanyak 117 orang $(59,7 \%)$ terlepas dari apakah kunjungan ini mengakibatkan anak dirawat atau pulang dari rumah sakit. Hal ini sesuai dengan penelitian yang dilakukan oleh $\mathrm{Li}$ et al (2013), Mace et al (2013) dan Keeble \& Kossarova (2017) dimana jumlah kunjungan pasien anak laki-laki lebih banyak dibandingkan jumlah kunjungan anak perempuan, penelitian ini juga menunjukkan bahwa tidak terdapat hubungan antara jenis kelamin dengan kunjungan pasien anak ke IGD.

Tabel 1. Karakteristik Responden Berdasarkan Jenis Kelamin dan Usia

\begin{tabular}{llcc}
\hline No & Karakteristik & Jumlah & \% \\
\hline 1 & Jenis Kelamin & & \\
& Laki-Laki & 117 & 59,7 \\
& Perempuan & 79 & 40,3 \\
& Usia & & \\
& Bayi & 43 & 21,9 \\
& Batita & 26 & 13,3 \\
& Pre school & 26 & 13,3 \\
& Sekolah & 52 & 26,5 \\
& Remaja & 49 & 25,0 \\
\hline & Total & 196 & 100 \\
\hline
\end{tabular}

Hasil penelitian ini juga menunjukkan bahwa mayoritas anak yang mendatangi IGD berada pada rentang usia sekolah dengan jumlah 52 orang (26,5\%). Hasil penelitian berbeda dengan penelitian yang dilakukan oleh Wier., Yu., Owens \& Washington (2006), Li et al (2013), dan Keeble \& Kossarova (2017) dimana usia anak yang berkunjung ke IGD berada pada rentang usia 1-4 tahun atau berada pada rentang preschool. Pada penelitian yang dilakukan oleh Li et al (2013) menunjukkan bahwa terdapat hubungan antara usia dengan LOS pasien anak di IGD.

\section{b. Faktor yang Mempengaruhi LOS Pasien Anak di IGD}

Penelitian ini menunjukkan bahwa variabel yang berpengaruh adalah cara kedatangan dengan nilai p-value 0,004, OR 2,544 $(0,870-7,445)$, pemeriksaan diagnostik dengan nilai $p$-value $<0,001$, OR 2,480 (0,917-6,705), dan disposisi final dengan $p$-value $<0,001$, OR 0,322 $(0,106-0,981)$. Dari ketiga variabel ini yang paling mempengaruhi adalah variabel cara kedatangan (tabel 2).

Hasil analisis bivariat menunjukkan bahwa terdapat hubungan antara cara kedatangan pasien dengan LOS pasien anak di IGD dengan p-value $0.004(<0,05)$. Pada penelitian ini didapatkan bahwa pasien rujukan memiliki LOS yang lebih lambat dibandingkan pasien yang datang sendiri. Berdasarkan hasil uji regresi logistik didapatkan bahwa pasien yang datang dengan rujukan memiliki LOS yang lebih lama dibandingkan dengan pasien yang datang sendiri, dimana pasien rujukan memiliki kesempatan 2,554 kali lebih lambat dibandingkan yang datang sendiri.

Hasil penelitian ini didukung oleh penelitian yang dilakukan oleh Crilly et al (2015), menunjukkan bahwa terdapat hubungan cara kedatangan pasien dengan LOS pasien di IGD dengan nilai signifikansi $<0,05$, selain itu pasien yang datang dengan rujukan dan dibawa dengan ambulans memiliki kesempatan mengalami LOS yang lebih lama sebanyak 1,65 kali dibandingkan pasien yang datang sendiri. Hal ini terjadi karena pasien rujukan melewati berbagai proses, termasuk proses administrasi yang lebih banyak sebelum akhirnya dapat dipindahkan ke ruangan.

Hasil penelitian ini juga menunjukkan bahwa tidak terdapat hubungan antara jenis kasus dengan LOS pasien anak di IGD dengan p-value 0,793 (> 0,05). Pasien non trauma memiliki LOS yang lebih lambat dibandingkan dengan pasien trauma. Hal ini berbeda dengan penelitian yang dilakukan oleh Biber et al (2012) dimana terdapat hubungan antara jenis kasus dengan LOS pasien di IGD, namun median LOS pada penelitian ini menunjukkan bahwa pasien non trauma memiliki LOS yang lebih lama dibandingkan pasien trauma. Selain itu penelitian yang dilakukan oleh Rose et al (2012) membandingkan antara LOS pasien trauma yang menggunakan ventilator dengan LOS pasien non trauma yang menggunakan ventilator di IGD menunjukkan terdapat perbedaan yang signifikan, dimana pasien trauma memiliki LOS yang lebih lama dibandingkan non trauma dengan $p$-value $<0,05$. Hal ini dikarenakan pasien trauma membutuhkan banyak pemeriksaan dan tindakan tertentu, sehingga membutuhkan waktu yang lebih lama dibandingkan kasus non trauma

Faktor lain yang memiliki berpengaruh terhadap LOS pasien adak di IGD adalah konsultasi dokter spesialis, dimana hasil 
penelitian ini menunjukkan bahwa terdapat hubungan antara konsultasi dokter dengan LOS pasien anak di IGD RSUD dengan $p$-value 0,003 $(<0,05)$. Pasien yang mendapatkan konsultasi dokter spesialis memiliki LOS yang lebih lambat dibandingkan dengan pasien yang tidak konsultasi. Hal ini sesuai dengan penelitian yang dilakukan oleh Mahsanlar et al., (2014),
Erenler et al (2015), dimana terdapat hubungan antara konsultasi dokter spesialis dengan LOS pasien di IGD, disamping itu pasien yang konsultasi dengan satu dokter spesialis memiliki LOS yang lebih cepat dibandingkan pasien yang konsultasi dengan dua dokter spesialis.

Tabel. 2 Faktor yang Mempengaruhi LOS Pasien Anak di IGD

\begin{tabular}{|c|c|c|c|c|c|c|c|c|}
\hline \multirow{3}{*}{ Variabel } & \multicolumn{4}{|c|}{ Length of Stay } & \multirow{2}{*}{\multicolumn{2}{|c|}{ Total }} & \multirow{3}{*}{ OR $(95 \% \mathrm{CI})$} & \multirow{3}{*}{ p value } \\
\hline & \multicolumn{2}{|c|}{ Cepat } & \multicolumn{2}{|c|}{ Lambat } & & & & \\
\hline & $\mathbf{N}$ & $\%$ & $\mathbf{N}$ & $\%$ & $\mathbf{N}$ & $\%$ & & \\
\hline \multicolumn{9}{|l|}{ Cara Kedatangan } \\
\hline Rujukan & 22 & 35,5 & 40 & 64,5 & 62 & 100 & \multirow{2}{*}{$\begin{array}{c}0,245 \\
(0,89-0,673)\end{array}$} & \multirow[t]{2}{*}{$0,004^{*}$} \\
\hline Sendiri & 75 & 56,0 & 59 & 44,0 & 134 & 100 & & \\
\hline \multicolumn{9}{|l|}{ Jenis Kasus } \\
\hline Trauma & 23 & 47,0 & 26 & 53,0 & 49 & 100 & \multirow{2}{*}{$\begin{array}{c}1,128 \\
(0,459-2,774)\end{array}$} & \multirow[t]{2}{*}{0,793} \\
\hline Non Trauma & 74 & 50,3 & 73 & 49,7 & 147 & 100 & & \\
\hline \multicolumn{9}{|c|}{ Konsultasi dokter spesialis } \\
\hline $\mathrm{Ya}$ & 77 & 44,5 & 96 & 55,5 & 173 & 100 & \multirow{2}{*}{$\begin{array}{c}0,122 \\
(0,026-0,584)\end{array}$} & \multirow[t]{2}{*}{$0,003^{*}$} \\
\hline Tidak & 20 & 86,9 & 3 & 13,1 & 23 & 100 & & \\
\hline \multicolumn{9}{|c|}{ Pemeriksaan Laboratorium } \\
\hline Ya & 80 & 44,9 & 98 & 55,1 & 178 & 100 & 0,268 & $0,000^{*}$ \\
\hline Tidak & 17 & 75 & 1 & 25 & 18 & 100 & \multicolumn{2}{|l|}{$(0,027-2,663)$} \\
\hline \multicolumn{9}{|c|}{ Pemeriksaan Diagnostik } \\
\hline Ya & 21 & 30,2 & 45 & 35,8 & 66 & 100 & \multirow{2}{*}{$\begin{array}{c}2,480 \\
(0,917-6,705)\end{array}$} & \multirow[t]{2}{*}{$0,000^{*}$} \\
\hline Tidak & 27 & 69,2 & 12 & 21,2 & 39 & 100 & & \\
\hline \multicolumn{9}{|l|}{ Waktu Kedatangan } \\
\hline Sift Pagi & 16 & 57,1 & 12 & 42,9 & 28 & 100 & & \multirow[t]{3}{*}{0,332} \\
\hline Sift Sore & 14 & 38,9 & 22 & 61,1 & 36 & 100 & \multirow{2}{*}{$(0,552-1,717)$} & \\
\hline Sift Malam & 18 & 43,9 & 23 & 56,1 & 41 & 100 & & \\
\hline \multicolumn{9}{|l|}{ Disposisi Final } \\
\hline Rawat Inap & 26 & 34,2 & 50 & 41,3 & 76 & 100 & 0,322 & \multirow[t]{2}{*}{$0,000^{*}$} \\
\hline Pulang & 22 & 75,9 & 7 & 24,1 & 29 & 100 & $(0,106-0,981)$ & \\
\hline
\end{tabular}

Berdasarkan hasil wawancara dengan kepala instalasi IGD, konsultasi dokter dilakukan setiap pasien membutuhkan penanganan dokter spesialis. Konsultasi dokter spesialis dilakukan sesuai dengan dokter penanggung jawab pelayanan (DPJP) yang ditugaskan pada hari itu. Pada sift pagi pasien yang dikonsulkan akan dikunjungi langsung oleh DPJP, sedangkan pada sift sore dan malam konsultasi dilakukan melalui telepon.

Selain itu faktor yang berhubungan dengan LOS pasien anak di IGD adalah pemeriksaan laboratorium, dimana hasil analisis bivariat pada penelitian ini menunjukkan bahwa terdapat hubungan antara pemeriksaan laboratorium dengan LOS pasien anak di IGD dengan nilai $p$-value $<0,001$. Hal ini berbeda dengan penelitian yang dilakukan oleh Budiarsana (2015), dimana tidak terdapat hubungan antara pemeriksaan laboratorium dengan LOS pada pasien di IGD. Pemeriksaan laboratorium merupakan pemeriksaan penunjang yang dibutuhkan untuk penegakan diagnosa pasien, pemeriksaan laboratorium yang dilakukan di laboratorium IGD RSUD merupakan pemeriksaan kimia darah tertentu, pemeriksaan laboratorium rutin dan analisis gas darah, untuk pemeriksaan yang kompleks dilakukan bila pasien telah stabil ataupun setelah berada di ruangan.

Hasil penelitian ini juga menunjukkan bahwa terdapat hubungan antara pemeriksaan diagnostik dengan LOS pasien anak di IGD, pasien yang melakukan pemeriksaan diagnostik memiliki LOS yang lebih lambat dibandingkan pasien yang tidak, dimana pasien yang dilakukan pemeriksaan diagnostik memiliki kesempatan LOS 0,207 kali lebih lambat dibandingkan dengan pasien yang tidak dilakukan pemeriksaan diagnostik.

Hasil penelitian ini didukung juga oleh penelitian yang dilakukan oleh Mace et al (2013), Li et al (2013), dan Keeble \& Kossarova (2017), dimana terdapat hubungan yang signifikan 
antara pemeriksaan diagnostik dengaan LOS pasien di IGD. Setiap pasien yang menjalani pemeriksaan diagnostik membutuhkan waktu yang lebih lama, dimulai dari persiapan hingga pembacaan hasil. Penelitian yang dilakukan oleh Prisk, Godfrey, \& Lawrence (2016) didapatkan bahwa LOS pasien dengan pemeriksaan sinar- $X$ adalah 171,8 menit, sedangkan pasien yang tidak mendapatkan pemeriksaan diagnostik 131,5 menit.

Hasil analisis bivariat pada penelitian ini (Tabel 2) menunjukkan bahwa tidak terdapat hubungan antara waktu kedatangan dengan LOS pasien anak di IGD dengan $p$-value 0,332 (> $0,05)$. Hasil penelitian ini didukung oleh penelitian yang dilakukan oleh Mahsanlar et al (2014), di rumah sakit Turki dimana LOS pada rentang waktu jam 16.00-00.00 7 jam 16 menit dengan jumlah kunjungan pasien sebanyak 263 pasien, kemudian pada pukul 00.00-08.00 terjadi penurunan jumlah kunjungan pasien yaitu sebanyak 118 orang dengan LOS 8 jam 22 menit, selain itu penelitian yang dilakukan oleh Wier et al (2015), bahwa LOS pasien yang datang pada malam hari lebih panjang dibandingkan pasien yang datang di pagi atau sore hari.

\section{c. Analisis Faktor Yang Mempengaruhi LOS pasien anak di IGD}

Penelitian ini menunjukkan bahwa variabel yang berpengaruh adalah cara kedatangan dengan nilai $p$ 0,088, OR 2,544 (0,870-7,445), pemeriksaan diagnostik dengan nilai $p 0,908$, OR 2,480 (0,917-6,705), dan disposisi final dengan $p$-1,134, OR $0,322 \quad(0,106-0,981)$. Berdasarkan hasil uji regresi logistik didapatkan bahwa pasien yang datang dengan rujukan memiliki LOS yang lebih lama dibandingkan dengan pasien yang datang sendiri, dimana pasien rujukan memiliki kesempatan 2,554 kali lebih lambat dibandingkan yang datang sendiri (tabel 3).

Hasil penelitian ini sejalan dengan hasil penelitian yang dilakukan oleh Crilly et al (2015) dimana pasien yang datang dengan rujukan dan dibawa dengan ambulans memiliki kesempatan mengalami LOS yang lebih lama sebanyak 1,65 kali dibandingkan pasien yang datang sendiri. Hal ini terjadi karena pasien rujukan melewati berbagai proses, termasuk proses administrasi yang lebih banyak sebelum akhirnya dapat dipindahkan ke ruangan.

Pada penelitian ini didapatkan bahwa pasien yang mendapatkan pemeriksaan diagnostic memiliki LOS yang lebih lama dbandingkan dengan pasien yang tidak, dimana pasien yang dilakukan pemeriksaan diagnostik memiliki kesempatan LOS 2,480 kali lebih lama dibandingkan dengan pasien yang tidak. Penelitian ini sejalan dengan penelitian yang dilakukan oleh van der Veen et al (2018), dimana pasien yang dlakukan pemeriksaan radiologi memiliki kesempatan LOS 3,2 $(2,13-4,30)$ kali lebih lama dbandngkan pasien yang tidak dilakukan pemeriksaan diagnostik, disamping itu berdasarkan penelitan yang dilakukan oleh Kocher et al (2012), menunjukkan bahwa setap pemerksaan diagnostic memiliki kesempatan LOS 1,48 $(1,11-1,96)$ kali lebih lama dbandingkan pasien yang tidak dilakukan pemerksaan dagnostik.

Tabel 3 Analisis Faktor yang Mempengaruhi LOS Pasien Anak di IGD

\begin{tabular}{|c|c|c|c|c|}
\hline & Variabel & Koefisien & p value & OR (IK95\%) \\
\hline \multirow[t]{5}{*}{ Langkah 1} & Cara kedatangan rujukan & 0,922 & 0,092 & $2,513(0,860-7,343)$ \\
\hline & Dilakukan konsultasi ke dokter spesialis & 0,559 & 0,586 & $1,750(0,233-13,116)$ \\
\hline & Mendapatkan pemeriksaan diagnostik & 0,865 & 0,097 & $2,376(0,855-6,605)$ \\
\hline & Disposisi final pasien pulang & $-1,034$ & 0,105 & $0,356(0,102-1,243)$ \\
\hline & Konstanta & -0.219 & 0,877 & 0,803 \\
\hline \multirow{3}{*}{ Langkah 2} & Mendapatkan pemeriksaan diagnostik & 0,851 & 0,102 & $2,342(0,845-6,495)$ \\
\hline & Disposisi final pasien pulang & $-1,001$ & 0,114 & $0,368(0,106-1,273)$ \\
\hline & Konstanta & $-0,704$ & 0,480 & 0,495 \\
\hline Langkah 3 & Cara kedatangan rujukan & 0,934 & 0,088 & $2,544(0,870-7,445)$ \\
\hline
\end{tabular}


Berdasarkan hasil analiss multivariate (Tabel 3) penelitian ini didapatkan juga bahwa disposisi final pasien mempengaruhi LOS pasien anak di IGD, dimana pasien pulang memiliki LOS yang lebih cepat dbandingkan pasien yang dirawat. Penelitian ini sejalan dengan penelitian yang dilakukan oleh Casalino et al (2014), dimana pasien pulang memiliki LOS yang lebih cepat dibandngkan pasien drawat atau dirujuk, dimana pasien yang drawat druang medikal atau bedah memiliki LOS 0,61 (0,54-0,68) kali memiliki LOS lebh lama dibandngkan pasien pulang, dan pasien rujukan memiliki LOS 1,79 $(1,54-2,07)$ kali memiliki LOS lebih lama dbandngkan pasien pulang. Berdasarkan hasil penelitian yang dilakukan oleh van der Veen et al (2018) didapatkan bahwa pasien pulang membutuhkan waktu sekitar 74-117 menit untuk pulang setelah keputusan diambil

\section{Simpulan dan Saran}

Berdasarkan hasil penelitian ini dapat disimpulkan bahwa mayoritas responden yang mengunjungi IGD adalah anak laki-laki dengan rentang usia sekolah. Hasil penelitian ini juga menunjukkan bahwa, cara kedatangan, konsultasi dokter spesialis, disposisi final, pemeriksaan laboratorium dan diagnostic berisiko memperpanjang LOS pasien anak di IGD. Berdasarkan hasil penelitian ini, dibutuhkan sebuah protokol dan kebijakan terutama terkait alur penerimaan pasien rujukan dan pasien datang sendiri sehingga dapat mengembangkan dan meningkatkan kualitas ruangan.

\section{Ucapan Terima Kasih}

Terima kasih disampaikan kepada RSUD Arifin Achmad Pekanbaru yang telah memberikan izin terhadap penelitian ini. Terimaksih kepada Fakultas Keperawatan Universitas Riau yang telah mendanai penelitian ini.

\section{Daftar Pustaka}

Australasian College for Emergency Medicine. (2012). S11 Statement on hospital emergency department services for children.

www.acem.org.au/Standards-Publication s/Policies-Guidelines.aspx.

Budiarsana, I. P. (2015). Description of patient flow in an Indonesian emergency departmant of a major teaching hosptial (Doctoral dissertation).

Chonde, S., Nembhard, D., Kremer, G. E. O., \& Ashour, O. (2013). Neural Networks, Bayesian Networks, and Logistic Regression for ESI Prediction. In IIE Annual Conference. Proceedings (p. 1478). Institute of Industrial and Systems Engineers (IISE).

Crilly, J., Keijzers, G., Tippett, V., O'dwyer, J., Lind, J., Bost, N., ... \& Wallis, M. (2015). Improved outcomes for emergency department patients whose ambulance off-stretcher time is not delayed. Emergency Medicine Australasia, 27(3), 216-224.

Dharmawati, I., Setyaningtyas, A., \& Kusumastuti, N. P. (2017). Profile of Patients at Pediatric Emergency Services Soetomo Hospital Surabaya. Jurnal Ners, 7(2), 131-135.

Excellence, B. P. (2013). The Joint Commission announces 2014 national patient safety goal. Joint Commission Perspectives.

Gardner, R. L., Sarkar, U., Maselli, J. H., \& Gonzales, R. (2007). Factors associated with longer ED lengths of stay. The American journal of emergency medicine, 25(6), 643-650.

Golüke, N. M. S., Huibers, C. J. A., Stalpers, S. C., Taekema, D. G., Vermeer, S. E., \& Jansen, P. A. F. (2015). An observational, retrospective study of the length of stay, and its influencing factors, among elderly patients at the Emergency Department. European Geriatric Medicine, 6(4), 331-335.

Goto, T., Hasegawa, K., Faridi, M. K., Sullivan, A. F., \& Camargo Jr, C. A. (2017). Emergency Department Utilization by Children in the USA, 2010-2011. Western Journal of Emergency Medicine, 18(6), 1042.

Herring, A., Wilper, A., Himmelstein, D. U., Woolhandler, S., Espinola, J. A., Brown, D. F., \& Camargo Jr, C. A. (2009). Increasing length of stay among adult visits to US emergency departments, 2001-2005. Academic Emergency Medicine, 16(7), 609-616.

Horwitz, L. I., Green, J., \& Bradley, E. H. (2010). US emergency department performance on wait time and length of visit. Annals of emergency medicine, 55(2), 133-141. 
Keeble, E., \& Kossarova, L. (2017). Focus on: Emergency hospital care for children and young people. Focus On Research Report. QualityWatch.

Kreindler, S. A., Cui, Y., Metge, C. J., \& Raynard, M. (2015). Patient characteristics associated with longer emergency department stay: a rapid review. Emerg Med J, emermed-2015.

Li, S. T., Chiu, N. C., Kung, W. C., \& Chen, J. C. (2013). Factors affecting length of stay in the pediatric emergency department. Pediatrics \& Neonatology, 54(3), 179-187.

Mace, S. E., Stephens, A., Amato, C., Barata, I., Benjamin, L., Dietrich, A., \& Sharieff, G. (2013). A Prospective, Multicenter Study of Factors Affecting the Emergency Department Length of Stay of Pediatric Patients: Does the Diagnosis, Especially Psychiatric Diagnosis, Matter?. Annals of Emergency Medicine, 62(4), S69-S70.

Mahsanlar, Y., Parlak, I., Yolcu, S., Serhat, A. K. A. Y., Demirtas, Y., \& Eryigit, V. (2014). Factors affecting the length of stay of patients in emergency department observation units at teaching and research hospitals in Turkey. Turkish journal of emergency medicine, 14(1), 3-8.

Pandee, U., Vallipakorn, S. A. O., \& Plitponkarnpim, A. (2015). The profile of pediatric patients visit emergency department at urban University Hospital in Thailand. J Med Assoc Thai, 98(8), 761-7.

Prisk, D., Godfrey, A. J. R., \& Lawrence, A. (2016). Emergency Department Length of Stay for Maori and European Patients in New Zealand. Western Journal of Emergency Medicine, 17(4), 438.

Ronca, K. (2014). Reducing wait time with the Emergency Severity Index 5 Level Triage Algorithm in the Emergency Department (Doctoral dissertation, Fairleigh Dickinson University).

Rose, L., Gray, S., Burns, K., Atzema, C., Kiss, A., Worster, A.,... \& Lee, J. (2012). Emergency department length of stay for patients requiring mechanical ventilation: a prospective observational study. Scandinavian journal of trauma, resuscitation and emergency medicine, 20(1), 30.

Sayah, A., Rogers, L., Devarajan, K., Kingsley-Rocker, L., \& Lobon, L. F. (2014). Minimizing ED waiting times and improving patient flow and experience of care. Emergency medicine international, 2014.

WHO. (2016). Paediatric emergency triage, assessment and treatment: care of critically-ill children. Geneva: WHO.

Wier, L. M., Yu, H., Owens, P. L., \& Washington, R. (2006). Overview of children in the emergency department, 2010: statistical brief\# 157. 